International Journal of Engineering \& Technology, $7(2.7)(2018) 848-853$
International Journal of Engineering \& Technology
SPC
Website: www.sciencepubco.com/index.php/IJET
Research Paper

\title{
Comparative Analysis of Edge Feeding and coaxial Feeding Technique with Fixed Frequency
}

\author{
S.S. Mohan Reddy ${ }^{1 *}$, M. Vinod Kumar ${ }^{1}$, B. Sanjay ${ }^{1}$, K. Aruna Kumari ${ }^{2}$ \\ Associate professor ${ }^{1^{*}}$ \\ ${ }^{I}$ Department of ECE, SRKR Engineering College, Bhimavaram, Andhra Pradesh, India \\ ${ }^{2}$ Department of CSE, SRKR Engineering College, Bhimavaram, Andhra Pradesh, India \\ *Email: rahulmohan720@gmail.com
}

\begin{abstract}
The performance of rectangular microstrip patch antenna with the edge feeding and coaxial feeding techniques with DGS (Defective ground structure) and DSS (Defective substrate structure) are analyzed. It was observed that the return loss for Edge feeding is $-28.39 \mathrm{~dB}$, for DSS it is - 26.44 and return loss for coaxial with DGS is $-27.50 \mathrm{~dB}$ and for DSS is -28.52 . VSWR is approximately equal to 1 for all designs and also it was observed that the Gain is enhancement in Edge feeding and Bandwidth is improvement with coaxial feeding. The antenna designing and simulation is done by using the ANSOFT HFSS Software.
\end{abstract}

Keywords: Microstrip Antenna, Edge Feeding, Coaxial Feeding, Feeding Point.

\section{Introduction}

The designing of microstrip patch antennas has become a prominent research area in the present wireless technology [1] due to their low profiles, cost effective and easy to fabricate characteristics. The main application of the microstrip patch antenna are more useful in Vehicles based satellite links [2] and Global position satellite [3] and also in Radar for telemetry. Actually the wireless applications lies in the range of 2 to $12 \mathrm{GHZ}$. The designed antenna can be operated in multiband frequencies with the frequency range of $2.75 \mathrm{GHZ}$ to $9.95 \mathrm{GHZ}$.

In the earlier designed antenna [4] with the substrate height of $1.57 \mathrm{~mm}$ using $\mathrm{RT} / \mathrm{duriod} 5880$. It was observed the return loss is $30.79 \mathrm{~dB}$ with a bandwidth of $28 \mathrm{MHZ}$, Gain is $6.732 \mathrm{~dB}$ and they founded that the VSWR is approximately equal to 1.06.The designed antenna is found to give a enhanced bandwidth and with multiband operating frequencies when compared with the earlier antenna . The antenna designing and simulation is done by using the ANSOFT HFSS software [5].

\section{Feeding techniques}

The microstrip patch antenna can be fed in different ways. The most popular feeding techniques for the microstrip antennas

\section{LINE FEEDING \\ 2. COAXAIL FEEDING \\ 3. APERTURE COUPLE FEED \\ 4. PROXIMITY COUPLED FEED}

The type of Feeding technique [6] can show more impact on the antennas and also it can change the operating of the antennas. In general line feeding is of two types Edge feeding and Inset feeding. The line feeding can avoid a multilayer board whereas the coaxial feeding is very easy to fabricate and it can get the better matching impedance because the feed can be placed at any point on the patch. In aperture feeding technique, the

shielding is provided for the feed circuitry from antenna by a conducting plane to transmit energy to antenna. Proximity coupled feeding is also be

known as the electromagnetic coupling. This feeding technique utilizes dual substrates and the radiating patch is on the upper substrate. In this feeding technique there is an improvement in the bandwidth of about $13 \%$.

\section{Antenna design}

The main aim for a micro strip patch antenna design is to determine the patch dimensions necessary to satisfy the specific performance characteristics over the required frequency band.

Knowing the thickness of a substrate and dielectric constant the microstrip patch antenna which operates at the required resonant frequency band can be designed by using formulae stated in equation 1 to 7 . Here $\mathrm{h}$ is the height of a substrate and value is $1.57 \mathrm{~mm}$.

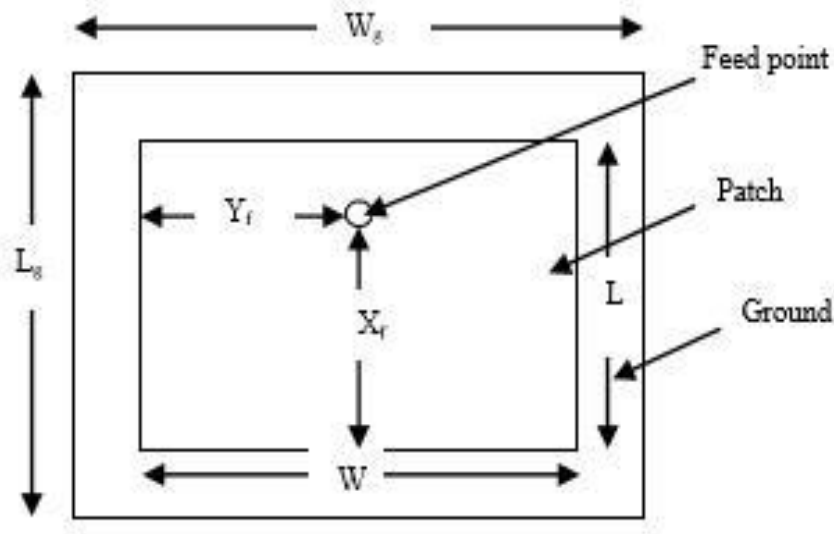

Fig. 1: Top view of micro strip patch antenna 
Step 1: calculation of width $(\mathrm{W})$

$$
\mathrm{W}=\frac{c}{2 f_{0} \sqrt{\frac{\varepsilon_{r}+1}{2}}}
$$

Step 2: Calculation of effective dielectric constant ( reff )

$$
\varepsilon_{\text {reff }}=\frac{\varepsilon_{r}+1}{2}+\frac{\varepsilon_{r}-1}{2}\left[1+12 \frac{h}{w}\right]^{-1 / 2}
$$

Step 3: Calculation of Effective Length (Leff)

$$
L_{e f f}=\frac{c}{2 f_{o} \sqrt{\varepsilon_{r e f f}}}
$$

Step 4: Calculation of length Extension $(\Delta \mathrm{L})$

$$
\Delta \mathrm{L}=0.412 \mathrm{~h} \frac{\left(\varepsilon_{\text {reff }}+0.3\right)\left(\frac{w}{h}+0.264\right)}{\left(\varepsilon_{\text {reff }}-0.258\right)\left(\frac{w}{h}+0.8\right)}
$$

Step 5: Calculation of actual length of patch (L)

$\mathrm{L}=\mathrm{L}_{\mathrm{eff}}-2 \Delta \mathbf{L}$

Step 6: Calculation of ground plane dimensions

$\mathrm{Lg}=6 \mathrm{~h}+\mathrm{L} 7$

$\mathrm{W}_{\mathrm{g}}=6 \mathrm{~h}+\mathrm{W}$

Where $\mathrm{Lg}_{\mathrm{g}}$ and $\mathrm{W}_{\mathrm{g}}$ are width and length of Ground

\section{Results and discussions}

The proposed antenna can be designed using the FR4 material with the Resonant frequency $2.4 \mathrm{GHZ}$ and height of the substrate is $1.57 \mathrm{~mm}$.

In this paper the designing of the Edge feeding antenna and coaxial feeding antenna is done using FR4 substrate same with the Resonant frequency and a comparison has been done on both the feeding techniques Table 1 and Table .2 show the parameter specifications for the both Edge feeding and coaxial feeding respectively.

Table 1: Dimensions of the patch for Edge feeding technique

\begin{tabular}{|l|c|c|}
\hline \multicolumn{1}{|c|}{ Parameter } & Dimensions & Units \\
\hline Height & 1.57 & $\mathrm{Mm}$ \\
\hline Frequency & 2.4 & $\mathrm{GHZ}$ \\
\hline Width of patch & 49.41 & $\mathrm{Mm}$ \\
\hline Length of patch & 41.36 & $\mathrm{Mm}$ \\
\hline Width of matching & 0.97 & $\mathrm{Mm}$ \\
\hline Length of matching & 17 & $\mathrm{Mm}$ \\
\hline Width of the feed Line & 4.912 & $\mathrm{Mm}$ \\
\hline Length of feed line & 43.02 & $\mathrm{Mm}$ \\
\hline Substrate & FR4_epoxy & \\
\hline
\end{tabular}

Table 2: Dimensions of patch for coaxial feeding Technique

\begin{tabular}{|l|c|c|}
\hline \multicolumn{1}{|c|}{ Parameter } & Dimensions & Units \\
\hline Frequency & 2.4 & $\mathrm{GHZ}$ \\
\hline Height & 1.57 & $\mathrm{Mm}$ \\
\hline Substrate & FR4_epoxy & \\
\hline Width of the patch & 49.41 & $\mathrm{Mm}$ \\
\hline Length of the patch & 38.36 & $\mathrm{Mm}$ \\
\hline DGS shape & Swastic & \\
\hline
\end{tabular}

\subsection{Edge feeding}

A microstrip with Edge feeding is designed with the length of patch as $41.36 \mathrm{~mm}$, width of the patch of the patch is $49.36 \mathrm{~mm}$, and resonant frequency is $2.4 \mathrm{GHZ}$. The selected antenna is found to have minimum return loss. The design of antenna without DGS is shown in Figure 2.

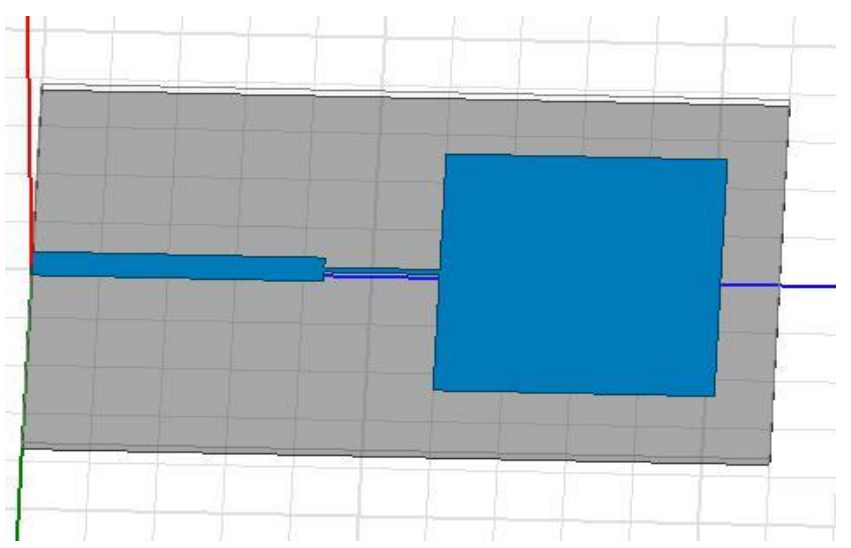

Fig. 2: Proposed antenna with Edge feeding

The designing of Rectangular microstrip patch antenna with swastic shaped DGS as shown in the Figure 3.

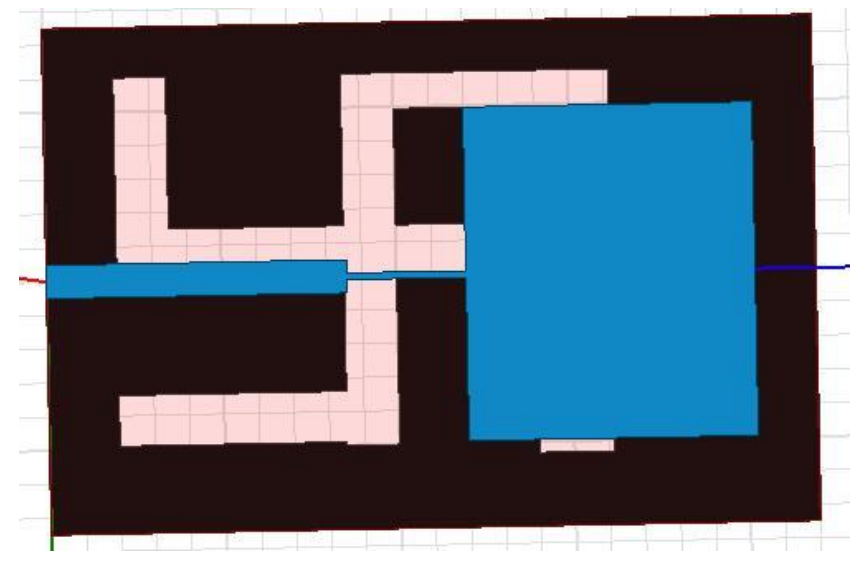

Fig. 3: Proposed antenna with DGS

The designing of proposed antenna with the DGS and Defective substrate structure with length of patch is $41.36 \mathrm{~mm}$ and width of the patch is $49.41 \mathrm{~mm}$ as shown in Figure 4. 


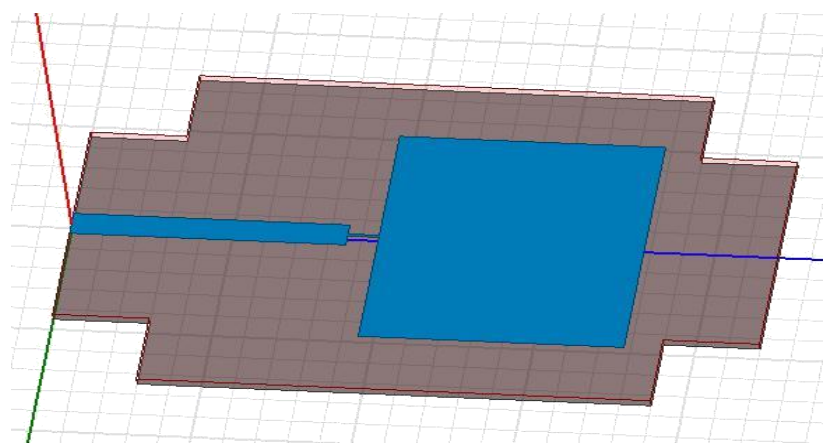

Fig. 4: Proposed antenna with DGS and DSS

\section{1) Return loss:}

Figure 5, 6, and 7 show the return loss of the proposed antenna with Edge feeding.

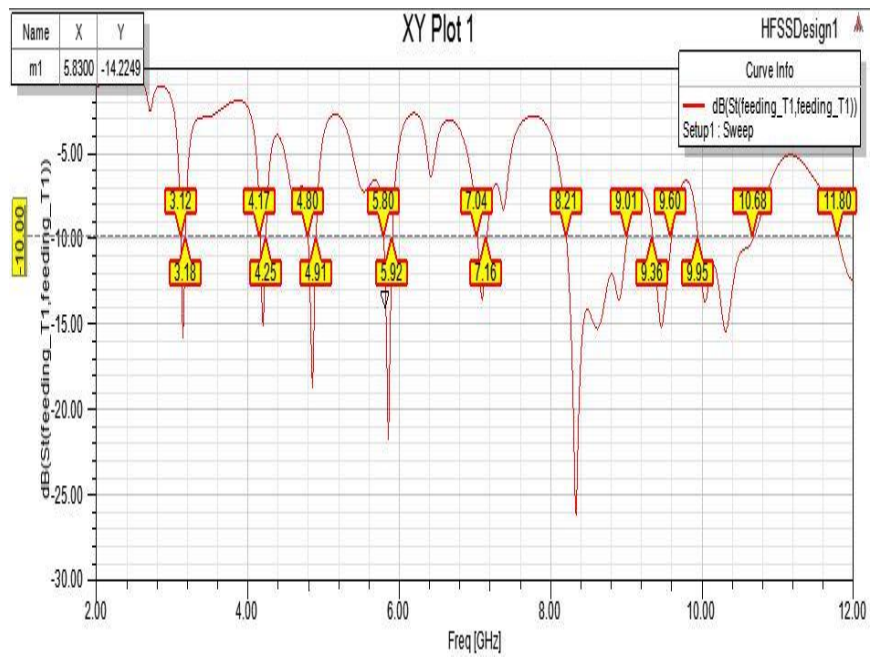

Fig. 5: Return loss vs. freq for the normal patch

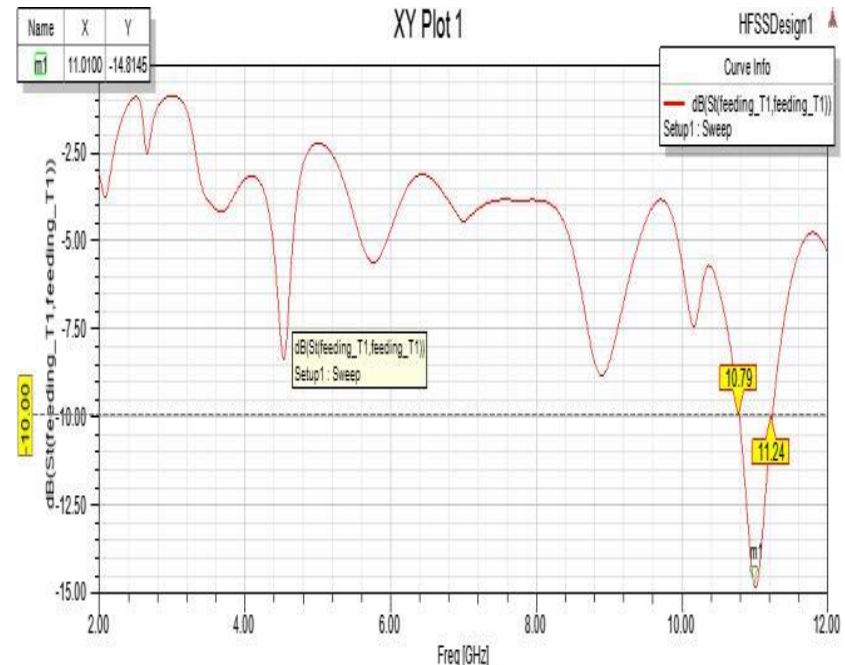

Fig.6: Return loss Vs. freq for the line feeding with DGS

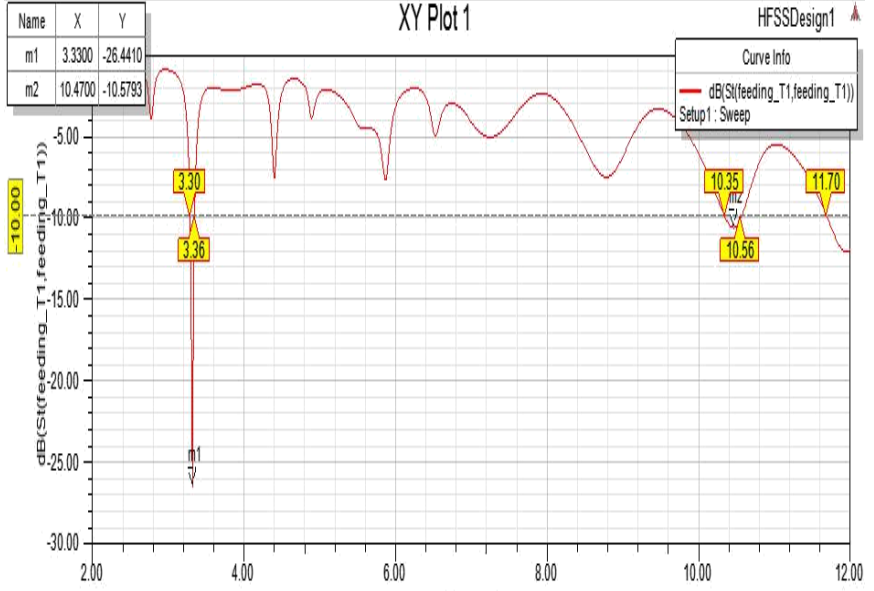

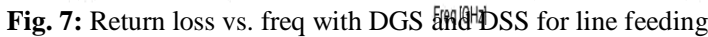

Figures 5 to 7 show the return loss for the Edge feeding. It was observed that the normal edge feeding operates in the multiband -26.49dB and with DGS the loss is low with single band.

\section{2) VSWR:}

Figure 8, 9, and 10 shows the VSWR of the microstrip patch antenna with the Edge feeding,

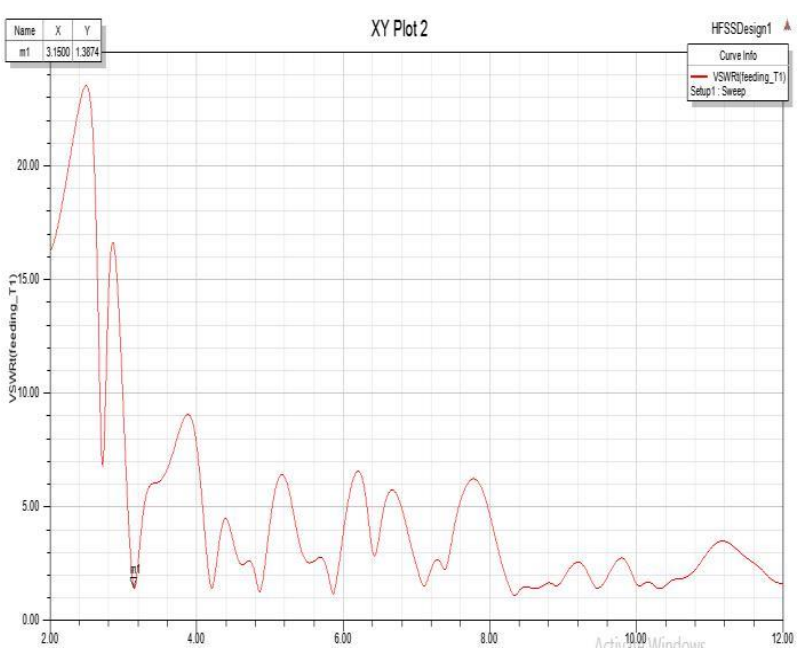

Fig. 8: VSWR vs. frequency for the normal line feeding

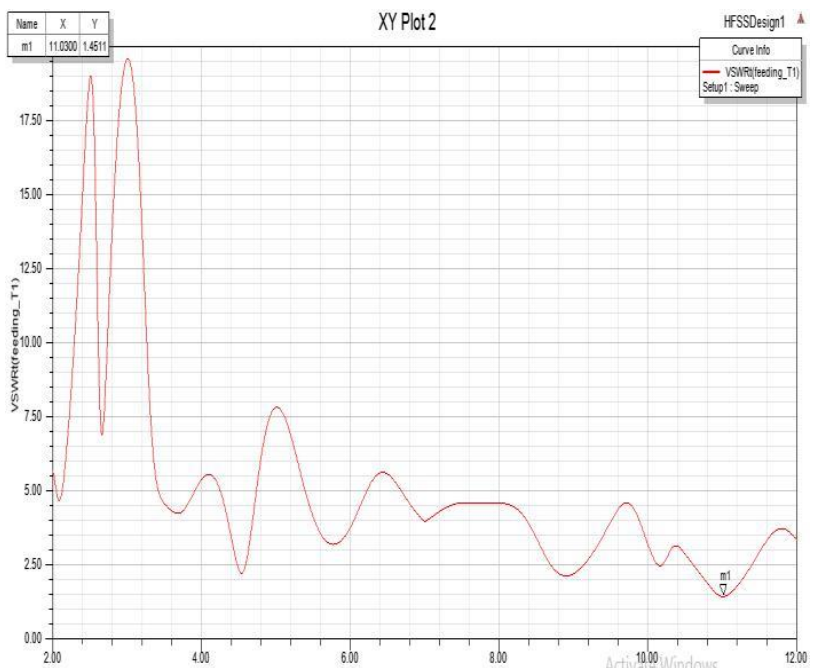

Fig. 9: VSWR vs. frequency for the line feeding with DGS 


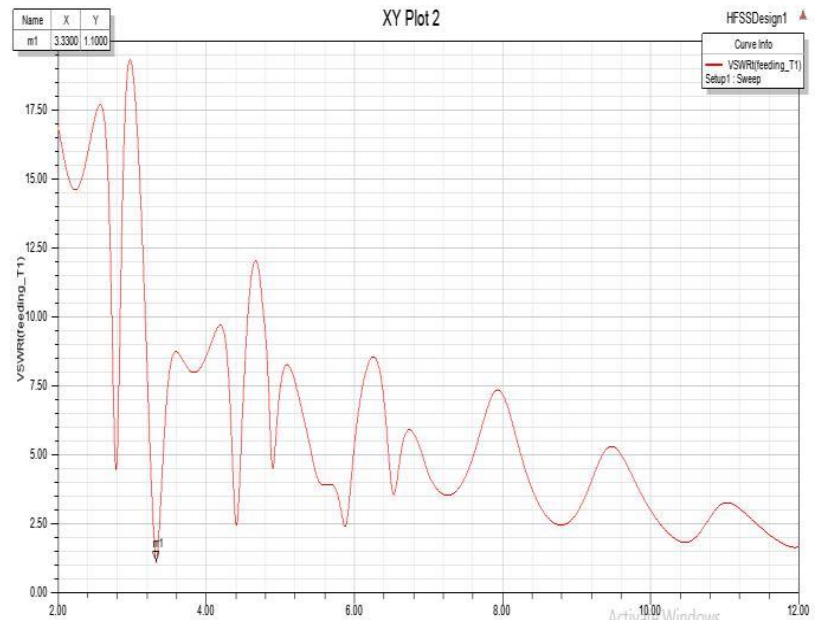

Fig. 10: VSWR vs. frequency for the line feeding with DGS and DSS

\section{3) Gain:}

Figure 11 to 13 shows the gain of the microstrip patch antenna with the Edge feeding. It was observed that the gain for normal ${ }^{1}$ patch is $6.1509 \mathrm{~dB}$, with DGS is $1.6017 \mathrm{~dB}$ and with both DGS and DSS is $4.1310 \mathrm{~dB}$.
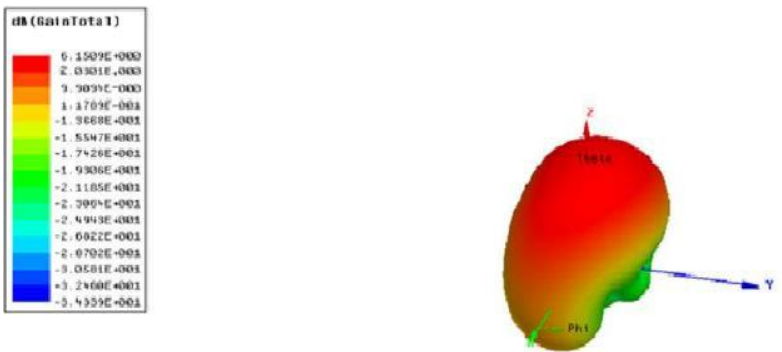

Fig. 11: Gain for the line feeding
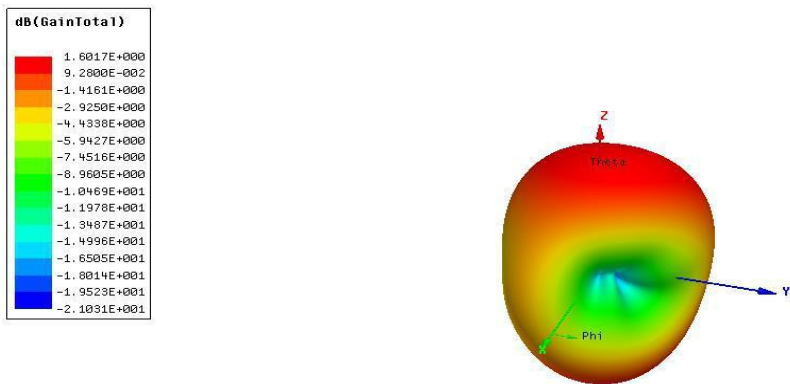

Fig. 12: Gain for the line feeding with DGS
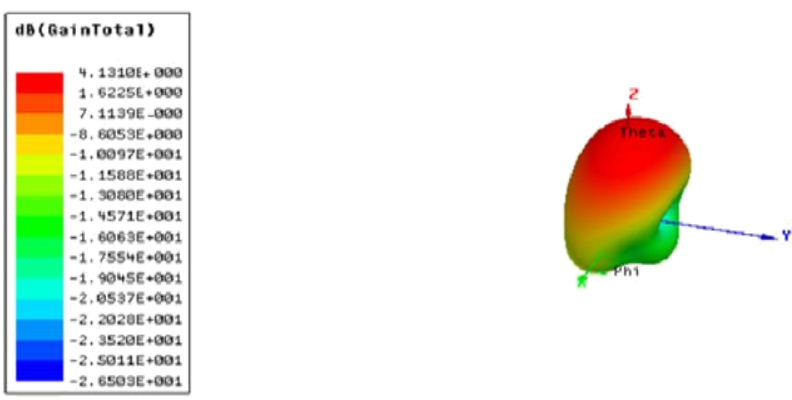

Fig. 13: Gain for the line feeding with DGS and DSS

\subsection{Coaxial Feeding}

A microstrip with Edge feeding is designed with the length of patch as $38.36 \mathrm{~mm}$, width of the patch of the patch is $49.41 \mathrm{~mm}$, and resonant frequency at $2.4 \mathrm{GHZ}$. The selected is found to have minimum return loss. The design antenna without DGS as shown in Figure 14.

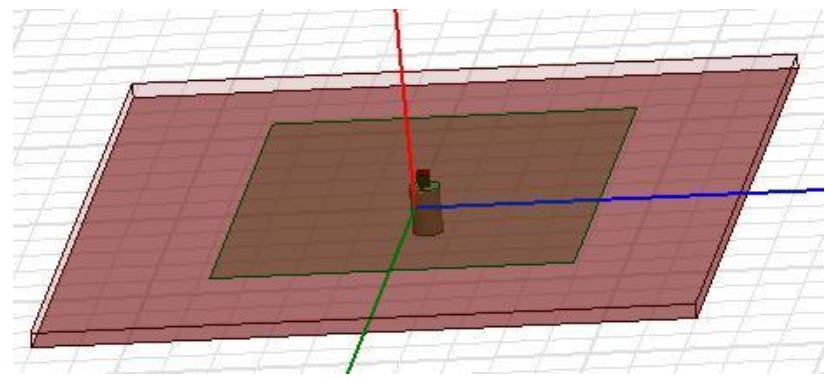

Fig. 14: Proposed antenna with the coaxial feeding.

The designing of patch antenna with swastic shaped DGS as shown the Figure 15.

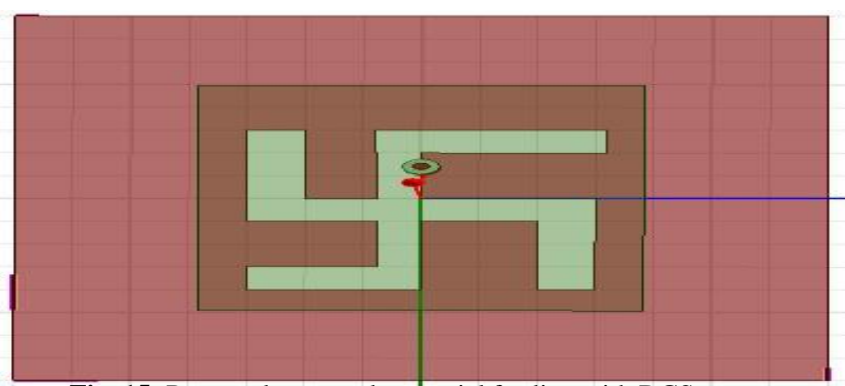

Fig. 15: Proposed antenna by coaxial feeding with DGS

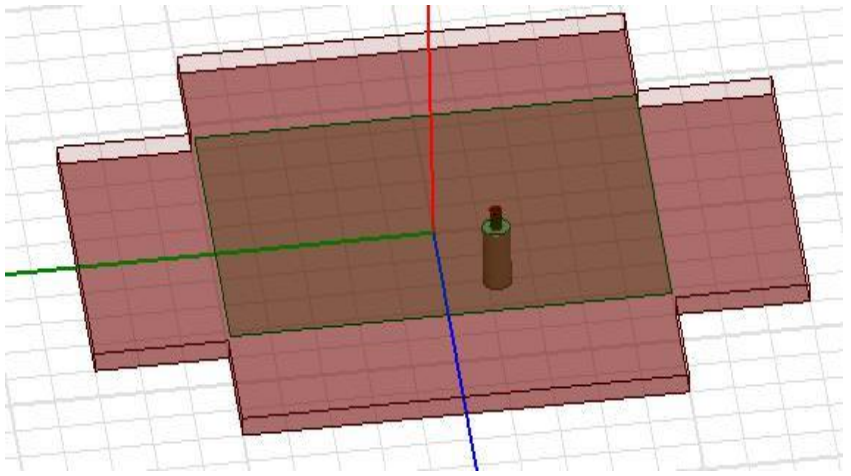

Fig. 16: Proposed antenna by coaxial feeding with DSS and DGS

\section{1) Return loss:}

Figure 17 to Figure 19 shows the return loss of the coaxial feeding for the microstrip patch antenna with DGS, DSS and without DGS

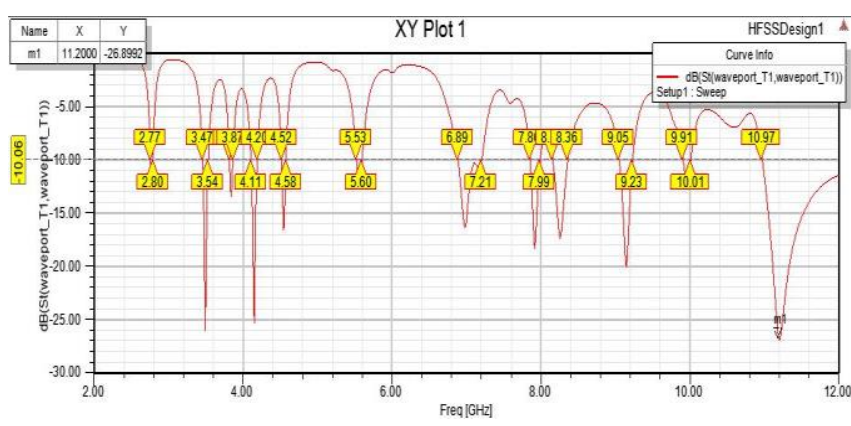

Fig. 17: Return loss Vs frequency for the normal coaxial feedin 


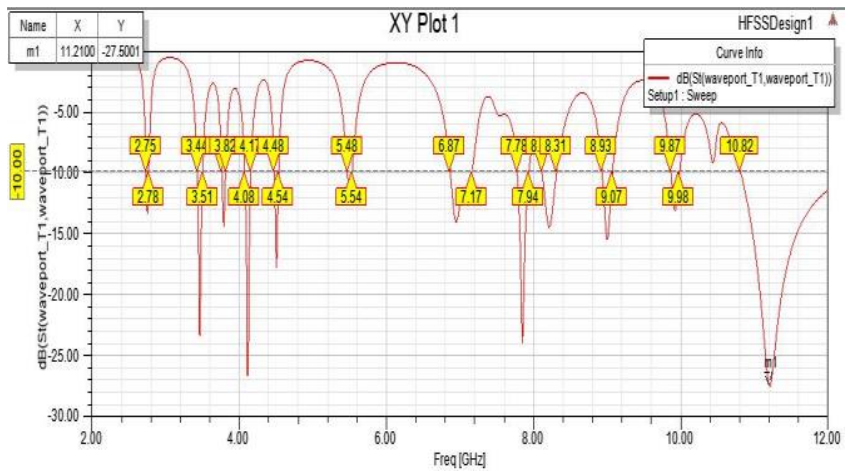

Fig. 18: Return loss vs. frequency for the coaxial feeding with DGS

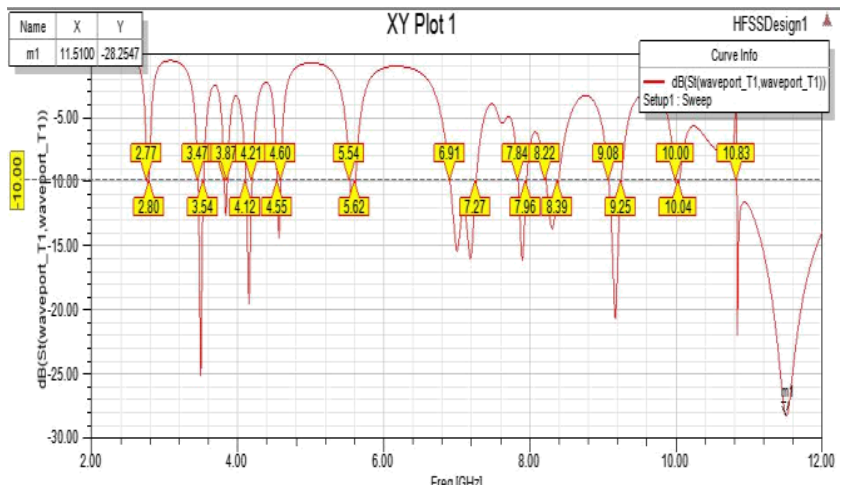

Fig. 19: Return loss vs. frequency for the coaxial feeding with DGS and DSS

It was founded that the return loss for the coaxial feeding is $-27 \mathrm{~dB}$ approximately with DGS and $-28 \mathrm{~dB}$ with DGS and DSS. It has observed that the multiband for all the designs using coaxial feeding.

\section{2) VSWR:}

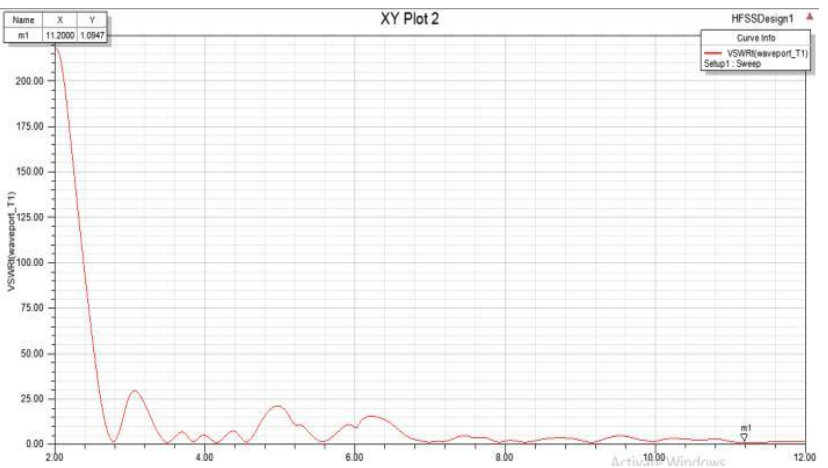

Fig. 19: VSWR vs. frequency for the normal coaxial feeding

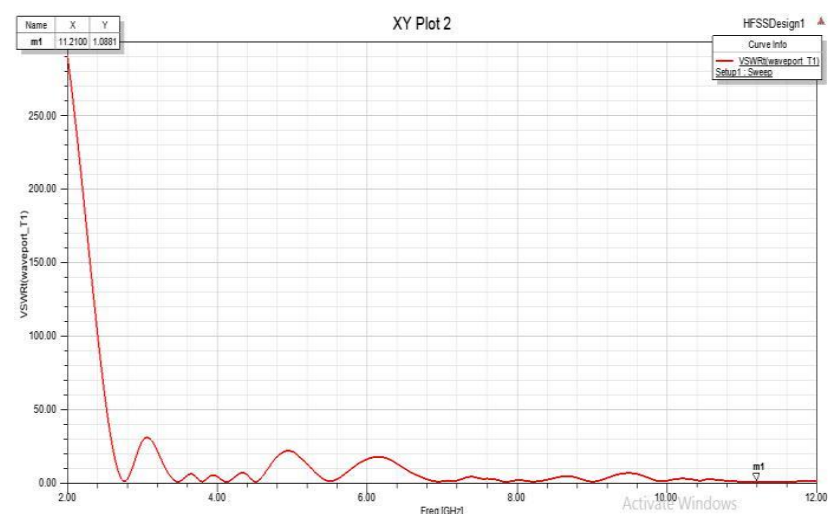

Fig. 20: VSWR vs. frequency for the normal coaxial feeding with DGS

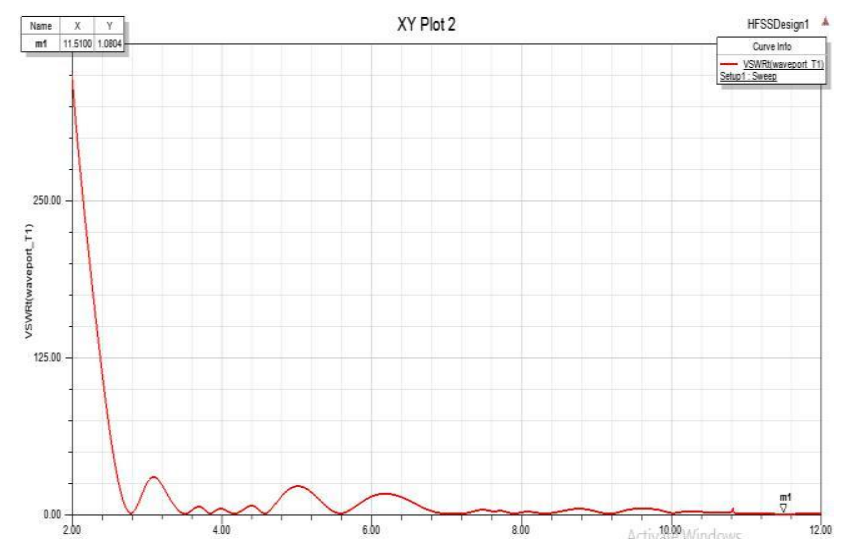

Fig. 21: VSWR vs. frequency for the normal coaxia feeding with DGS and DSS

The figures 19 to 21 show the VSWR for the coaxial feeding with and without DGS. The VSWR for all the designs is approximately equal to one.

\section{3) GAIN:}

Figure 22 to Figure.3.2.12 show the gain for the microstrip antenna with the coaxial feeding with and without DGS. The Gain for the coaxial feeding with the normal patch is $2 \mathrm{~dB}$, with DGS is $2.303 \mathrm{~dB}$ and with both DGS and DSS is $2.33 \mathrm{~dB}$

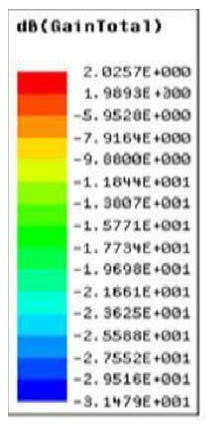

Fig. 22: Gain for the coaxial feeding
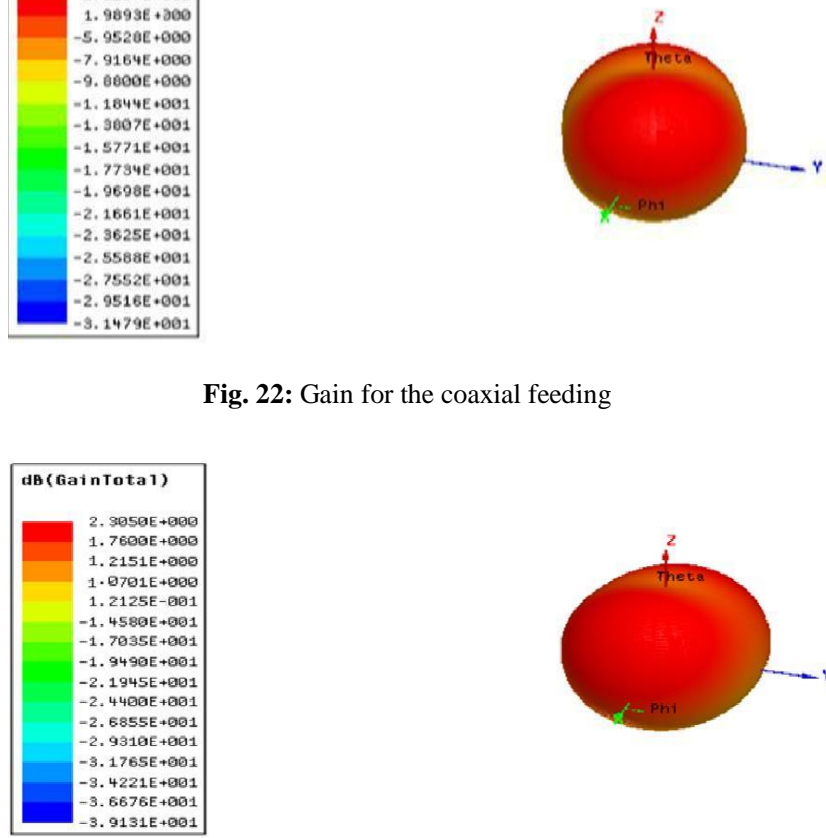

Fig. 23: Gain for the coaxial feeding with DGS
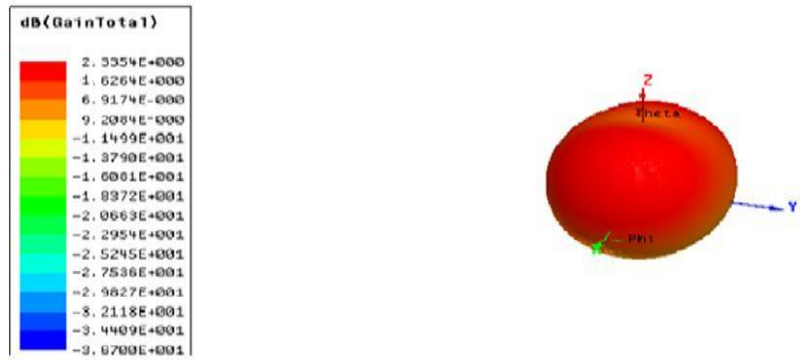

Fig. 24: Gain for the coaxial feeding with DGS and DSS 


\section{Comparison with the edge feeding with DGS and DSS with their responses}

Table 3 shows the comparison of the Edge feeding technique with normal patch and Edge feeding DGS and DSS.

Table 3: Comparison of the Edge feeding technique with DGS and DSS

\begin{tabular}{|c|c|c|c|}
\hline Parameter & $\begin{array}{c}\text { EDGE } \\
\text { FEEDING }\end{array}$ & $\begin{array}{c}\text { EDGE FEEDING } \\
\text { WITH DGS }\end{array}$ & \begin{tabular}{|c|} 
EDGE FEEDING \\
WITH DGS AND \\
DSS \\
\end{tabular} \\
\hline Return loss & $-26.12 \mathrm{Db}$ & $-14.81 \mathrm{~dB}$ & $-26.44 \mathrm{~dB}$ \\
\hline VSWR & 1.38 & 1.45 & 1.10 \\
\hline Gain $(d B)$ & 6.1509 & 1.6017 & 4.1310 \\
\hline Band & Multiple(7) & Single & Double \\
\hline Frequency (GHZ) & $\begin{array}{l}3.14,4.19,4 . \\
85,5.85,7.04 \\
, 8.34,9.45,1 \\
0.30\end{array}$ & 11.01 & $3.33,10.47$ \\
\hline Bandwidth (MHZ) & $60-800$ & 450 & 60,210 \\
\hline
\end{tabular}

Table 4 shows the comparison of the coaxial feeding with normal patch and coaxial feeding with DGS and DSS

Table 4: Comparison of the coaxial feeding technique with DGS and DSS.

\begin{tabular}{|c|c|c|c|}
\hline Parameter & $\begin{array}{l}\text { COAXIAL } \\
\text { FEEDING }\end{array}$ & $\begin{array}{c}\text { COAXIAL } \\
\text { FEEDING } \\
\text { WITH DGS }\end{array}$ & $\begin{array}{c}\text { COXAIL } \\
\text { FEEDING } \\
\text { WITH DGS } \\
\text { AND DSS } \\
\end{array}$ \\
\hline Return loss & $-26.89 \mathrm{~dB}$ & $-27.50 \mathrm{~dB}$ & $-28.58 \mathrm{~dB}$ \\
\hline VSWR & 1.09 & 1.02 & 1.08 \\
\hline $\operatorname{Gain}(\mathrm{dB})$ & 2.0206 & 2.303 & 2.33 \\
\hline Band & Multiple (12) & Multiple (12) & Multiple(12) \\
\hline Frequency (GHZ) & $\begin{array}{l}2.75,3.48,3.84, \\
4.15,4.53,5.55, \\
6.98,7.91,8.26, \\
9.14,9.95\end{array}$ & $\begin{array}{l}2.74,3.46,3.78,4 \\
.11,4.50,5.49,6 \\
94,7.83,8.21,9.0 \\
0,9.90\end{array}$ & $\begin{array}{l}2.76,3.47,3.83,4.1 \\
5,4.56,5.56,7.16,7 \\
88,8.31,9.16,10\end{array}$ \\
\hline Bandwidth (MHZ) & $30-320$ & $30-300$ & $30-170$ \\
\hline
\end{tabular}

Table 3 and Table 4 show the comparison of the coaxial feeding with DGS, DSS and Edge feeding with DGS and DSS. It is founded that the Edge feeding antenna will operates in single band with DGS and double band with DGS, DSS, and the coaxial feeding antenna operates in multiband with an improved bandwidth

\section{Conclusion}

The rectangular microstrip patch antenna with Edge feeding and Coaxial feeding technique by applying the Defective ground structure and Defective substrate structure has been discussed. In the earlier design antenna the bandwidth is $28 \mathrm{MHZ}$, return loss is $-30 \mathrm{~dB}$ As compared to the earlier design, it was observed that this antenna has enhanced bandwidth i.e.,, $730 \mathrm{MHZ}$ in edge feeding and $300 \mathrm{MHZ}$ in coaxial feeding and less return loss i.e.,, $-28.99 \mathrm{~dB}$ with coaxial feeding and improvement in the gain for the edge feeding techniques i.e.,, $6.15 \mathrm{~dB}, 4.13 \mathrm{~dB}$ and also these designed antennas are operated at the solution frequency of $2.4 \mathrm{GHZ}$

\section{References}

[1] O. Tipmongkolsilp, S. Zaghloul, and A. Jukan, "The evolution of cellular backhaul technologies: Current issues and future trends," IEEECommun. Surveys Tuts., vol. 13, no. 1, pp. 97-113, 1st Quart., 2011.

[2] Mailloux, R.J., et al, "microstrip antenna technology", IEEE Trans. Antennas and Propagation, Vol. AP-29, January 1981, pp.2-24.

[3] James, R.J., et al, "Some recent developments in microstrip antenna design", IEEE Trans. Antennas and Propagation, Vol.AP29, January 1981, pp.124-128.

[4] Hemant Kumar., et al "Design Characterization of Rectangular Microstrip Patch Antenna for Wi-Fi Application", IJCET Trans. Vol.4 No.2 (April 2004).
[5] Ansoft HFSS version 13: Overview.

[6] 6x9 Handbook /microstrip Antenna designing Handbook / Ramesh Garg et., / ISBN 0-89006-513-6 / Chapter 1 